\title{
Prognostic and predictive value of serum carcinoembryonic antigen levels in advanced non-small cell lung cancer patients with epidermal growth factor receptor sensitive mutations and receiving tyrosine kinase inhibitors
}

\author{
Xin Min Zhao ${ }^{1, *}$, Jing Zhao ${ }^{2, *}$, Kai Lin Xing ${ }^{1, *}$, Si Sun ${ }^{1}$, Zhi Guo Luo ${ }^{1}$, Hui Jie Wang ${ }^{1}$, \\ Jia Lei Wang ${ }^{1}$, Jian Hua Chang ${ }^{1}$ and Xiang Hua Wu ${ }^{1}$ \\ ${ }^{1}$ Department of Medical Oncology, Fudan University Shanghai Cancer Center; Department of Oncology, Shanghai Medical \\ College, Fudan University, Shanghai 200032, China \\ ${ }^{2}$ Department of Medical Oncology, Tongji University Affiliated Shanghai Pulmonary Hospital, Tongji University Medical School \\ Cancer Institute, Shanghai 200433, China \\ "These authors have contributed equally to this work \\ Correspondence to: Xiang Hua Wu, email: xhwu2015@yahoo.com \\ Keywords: non-small cell lung cancer, chemotherapy, epidermal growth factor receptor, tyrosine kinase inhibitors, \\ carcinoembryonic antigen \\ Received: October 13, $2016 \quad$ Accepted: May 14, $2017 \quad$ Published: August 10, 2017 \\ Copyright: Zhao et al. This is an open-access article distributed under the terms of the Creative Commons Attribution License 3.0 \\ (CC BY 3.0), which permits unrestricted use, distribution, and reproduction in any medium, provided the original author and source \\ are credited.
}

\section{ABSTRACT}

Background: Despite the widespread use of epidermal growth factor receptor (EGFR) tyrosine kinase inhibitors (TKIs) in advanced or recurrent non-small cell lung cancer (NSCLC), no biomarkers for predicting the efficacy of EGFR-TKIs in patients with EGFR-sensitive mutations have yet been identified. The purpose of our study was to explore the effect of baseline serum tumor markers in stage IIIB/IV NSCLC patients treated with EGFR-TKIs.

Methods: One hundred and seventy-seven patients with stage IIIB/IV NSCLC who harbored EGFR-sensitive mutations and were treated with EGFR-TKIs were retrospectively reviewed. Their levels of CEA, CYFRA 21-1, NSE and CA199 were measured before treatment with EGFR-TKIs.

Results: The response rate for all patients was $54.8 \%$, with a median progressionfree survival of $\mathbf{6 . 6}$ months and overall survival of $\mathbf{1 4 . 8}$ months. In univariate analyses, patients with CEA levels below the cutoff point $(10 \mathrm{ng} / \mathrm{ml})$ had higher RR, better PFS, and better OS than those with CEA levels above $10 \mathrm{ng} / \mathrm{mL}$ (RR: $69.2 \%$ vs. $43.4 \%$, $p=0.001$; mPFS: 7.8 months vs. 5.3 months, $p=0.029$; mOS: 18.8 months vs. 11.8 months, $p=0.000$ ). The baseline serum CEA level was an independent factor for $\mathbf{R}$ (odds ratio $[O R]=0.322, p=0.001$ ), PFS (hazard ratio $[H R]=1.45, p=0.025$ ), and OS $(H R=2.133, p=0.000)$.

Conclusion: Our study suggests that baseline serum CEA levels may play a role in predicting the efficacy of EGFR-TKIs in stage IIIB/IV NSCLC patients with EGFRsensitive mutations who are treated with EGFR-TKIs.

\section{INTRODUCTION}

Lung cancer is the leading cause of worldwide cancer deaths and is one of the most common cancers in both men and women. It has been estimated to account for over $25 \%$ of cancer-related deaths [1]. Approximately $80-85 \%$ of lung cancer patients are non-small-cell lung cancer (NSCLC), and approximately $40-50 \%$ of these patients are advancedstage NSCLC. The response rate of first-line chemotherapy is only approximately $30 \%$, and the median overall survival 
(OS) of patients with metastatic NSCLC is approximately one year [2]. Epidermal growth factor receptor (EGFR) is a proto-oncogene that regulates cell proliferation, metastasis, and angiogenesis [3]. EGFR mutations are known to strongly induce oncogenic potential in NSCLC [4]. In patients with EGFR mutations, it is well-established that classic mutations, such as in-frame deletions in exon 19 and the point mutation L858R in exon 21 , are associated with high sensitivity to EGFR tyrosine kinase inhibitors (TKIs). The initial response rate to first-generation EGFR TKIs is approximately $60-80 \%$ [5].

Tumor markers (TMs) are widely used in lung cancer management to evaluate the effectiveness of treatments, to monitor for metastases and recurrences after therapy, and to predict the effects of therapy. Carcinoembryonic antigen (CEA), cytokeratin 19 fragments (CYFRA 21-1) and neuron-specific enolase (NSE) are the most commonly used serologic markers for lung cancer management. Besides, CA199 is also an important biomarker for NSCLC.

Of the four TMs, CEA and CYFRA 21-1 are most frequently studied. CEA is a glycoprotein product of the gene CEACAM-5 and is a member of the immunoglobulin superfamily that serves as a cell-adhesion molecule and may also have an effect on innate immunity $[6,7]$. CEA is overexpressed in many malignant tumors, including NSCLC, and is readily detected in blood samples, making it valuable for prognosis and follow-up evaluations. High serum CEA levels have been identified as a prognostic factor in both resected NSCLC and in metastatic disease [6, 8-11]. CYFRA 21-1 is a fragment of cytokeratin (CK) 19. Serum CYFRA 21-1 levels have also been demonstrated to be a prognostic factor in patients with metastatic or recurrent NSCLC who receive therapy with EGFR TKIs. Pretreatment serum CYFRA 21-1 levels have been suggested to have prognostic value in patients with lung adenocarcinoma and advanced NSCLC who are receiving surgery [12-14].

However, it is unknown whether these TMs can be used as prognostic factors in patients with advanced lung adenocarcinoma and EGFR-sensitive mutations who are treated with EGFR TKIs. Therefore, in the present study, we investigated the impact of CEA, CYFRA 21-1, NSE and CA199 on the prognosis and prediction of TKI-treated stage IIIB and IV lung adenocarcinoma patients with EGFR-sensitive mutations.

\section{RESULTS}

\section{Patient characteristics}

A total of 177 patients ( 85 males and 92 females) with a median age of 60 years (range 31-80) were included in this analysis. Eighty-six patients received Erlotinib, and 91 patients were treated with Gefitinib. Ninety-four patients carried an exon 19 deletion mutation, 71 patients had an exon 21 point mutation, 8 patients had an exon 18 point mutation, and 16 patients had an exon 20 point mutation, with 10 patients harboring 2 mutations and 1 patient harboring 3 mutations. Among the 177 evaluable patients, 97 patients exhibited a partial response (PR), 24 patients exhibited stable disease (SD), and 56 patients exhibited progressive disease (PD), with an RR of 54.8\%. As of December $15^{\text {th }}, 2014,166$ patients $(93.8 \%)$ had progressed from the $(\mathrm{p}=0.001)$.disease, with a median PFS (mPFS) of 6.6 months (95\% confidence interval [CI] 5.28.0 months), and 134 patients $(75.7 \%)$ had died from any cause, with a median OS (mOS) of 14.8 months $(95 \%$ CI 12.1-17.5 months). As shown in Table 1, the demographic and clinical characteristics of patients with serum CEA levels below and above the cutoff point were balanced.

\section{Association between serum TM levels and RR, PFS, OS}

As shown in Table 2, the RRs of patients with CEA levels below and above the cutoff point were $69.2 \%$ and $43.4 \%$, respectively $(\mathrm{p}=0.001)$. The RRs of patients with CYFRA 21-1, NSE, and CA199 levels below the cutoff points were $61.3 \%, 53.1 \%$, and $58.2 \%$, respectively, while in patients with high CYFRA 21-1, NSE, and CA199 levels, the RRs were $50.5 \%, 56.8 \%$, and $51.3 \%$, without significant differences $(\mathrm{p}>0.05)$. No demographic or clinical factors were associated with RR.

\section{Serum CEA level is an independent predictive factor for PFS and OS in patients with EGFR mutations}

Kaplan-Meier curves for PFS according to the serum levels of single TMs are shown in Figure 1. Patients with serum CEA levels below $10 \mathrm{ng} / \mathrm{mL}$ displayed a significantly improved mPFS of 7.8 months $(95 \% \mathrm{CI}$, 7.0-8.6), vs. 5.3 months $(95 \% \mathrm{CI}, 3.6-7.0)$ for patients with higher CEA $(p=0.029)$. As for CYFRA 21-1, NSE, and CA199, there were no significant differences in mPFS between patients with low and elevated TM levels (CYFRA 21-1: 7.8 months [95\% CI, 6.6-9.0] vs. 5.9 months [95\% CI, 4.5-7.3], $\mathrm{p}=0.23$; NSE: 6.6 months [95\% CI, 4.6-8.6] vs. 6.9 months [95\% CI, 4.7-9.1], $\mathrm{p}=0.995$; CA199: 7.7 months [95\% CI, 6.1-9.3] vs. 5.6 months [95\% CI, 4.2-7.1], $\mathrm{p}=0.472$ ).

Figure 2 shows the Kaplan-Meier curves for OS according to the serum levels of single TMs. Patients with normal serum CEA exhibited a significantly longer mOS than those with elevated CEA (18.8 months [95\% CI, 13.4 - 24.2] vs. 11.8 months [95\% CI, 6.9 - 16.7], $\mathrm{p}=0.000$ ). No significant differences in mOS between patients with normal and high TM levels were observed (CYFRA 21-1: 14.5 months [95\% CI, 10.6 -18.4] vs. 16.5 months [95\% CI, 12.0-21.0], $\mathrm{p}=0.677$; NSE: 14.8 months [95\% CI, 10.6-19.0] vs. 14.9 months [95\% CI, 11.3-18.5], $\mathrm{p}=0.909$; CA199: 14.9 months [95\% CI, 11.0-18.8] vs. 14.4 months [95\% CI, 9.5-19.3], $\mathrm{p}=0.306$. 
Table 1: Demographic and clinical characteristics of patients with serum CEA levels

\begin{tabular}{|c|c|c|c|}
\hline \multirow[b]{2}{*}{ Characteristic } & \multicolumn{2}{|c|}{ CEA } & \multirow[b]{2}{*}{ P value } \\
\hline & $\begin{array}{c}\leq 10 \mathrm{ng} / \mathrm{mL}(\%) \\
(\mathrm{n}=78)\end{array}$ & $\begin{array}{c}>10 \mathrm{ng} / \mathrm{mL}(\%) \\
(\mathrm{n}=99)\end{array}$ & \\
\hline \multicolumn{4}{|l|}{ Age } \\
\hline$<60$ & $38(48.7)$ & $45(45.5)$ & 0.666 \\
\hline$\geq 60$ & $40(51.3)$ & $54(54.5)$ & \\
\hline \multicolumn{4}{|l|}{ Gender } \\
\hline female & $39(50.0)$ & $53(53.5)$ & 0.64 \\
\hline male & $39(50.0)$ & $46(46.5)$ & \\
\hline \multicolumn{4}{|l|}{ Smoker } \\
\hline non-smoker & $52(66.7)$ & $69(69.7)$ & 0.667 \\
\hline current or ever & $26(33.3)$ & $30(30.3)$ & \\
\hline \multicolumn{4}{|l|}{ T stage } \\
\hline 1 or 2 & $43(55.1)$ & $45(45.5)$ & 0.201 \\
\hline 3 or 4 & $35(44.9)$ & $54(54.5)$ & \\
\hline \multicolumn{4}{|l|}{$\mathrm{N}$ stage } \\
\hline negative & $20(25.6)$ & $17(17.1)$ & 0.169 \\
\hline positive & $58(74.4)$ & $82(82.9)$ & \\
\hline \multicolumn{4}{|l|}{ Pleural effusion } \\
\hline absent & $50(64.1)$ & $54(54.5)$ & 0.164 \\
\hline present & $27(35.9)$ & $45(45.5)$ & \\
\hline \multicolumn{4}{|l|}{ Lung metastasis } \\
\hline absent & $43(55.1)$ & $50(50.5)$ & 0.481 \\
\hline present & $34(44.9)$ & $49(49.5)$ & \\
\hline \multicolumn{4}{|l|}{ Brain metastasis } \\
\hline absent & $61(78.2)$ & $86(86.9)$ & 0.175 \\
\hline present & $16(20.5)$ & $13(13.1)$ & \\
\hline \multicolumn{4}{|l|}{ Bone metastasis } \\
\hline absent & $40(51.3)$ & $43(43.4)$ & 0.299 \\
\hline present & $38(48.7)$ & $56(56.6)$ & \\
\hline \multicolumn{4}{|l|}{ Liver metastasis } \\
\hline absent & $68(87.2)$ & $85(85.9)$ & 0.632 \\
\hline present & $9(12.8)$ & $14(14.1)$ & \\
\hline
\end{tabular}

$\mathrm{CEA}=$ carcinoembryonic antigen.

Multivariate analysis with a binary logistic regression model revealed that the serum CEA level before EGFR TKI treatment was an independent predictive factor for RR (odds ratio $[\mathrm{OR}]=0.322,95 \% \mathrm{CI}, 0.166$ $0.625, \mathrm{p}=0.001$;. Cox regression multivariate analysis demonstrated that CEA was independent predictive factor for PFS (hazard ratio $[\mathrm{HR}]=1.45,95 \% \mathrm{CI}, 1.047-2.008$, $\mathrm{p}=0.025)$ and for $\mathrm{OS}(\mathrm{HR}=2.133,95 \% \mathrm{CI}, 1.444-3.151$, $\mathrm{p}=0.000)($ Table 3$)$. 
Table 2: Association between factors and RR, PFS and OS

\begin{tabular}{|c|c|c|c|c|c|c|c|}
\hline \multirow[b]{2}{*}{ Factors } & \multicolumn{3}{|c|}{$\mathbf{R R}$} & \multicolumn{2}{|l|}{ PFS } & \multicolumn{2}{|l|}{ OS } \\
\hline & $\begin{array}{c}\text { Non- } \\
\text { responder }(\%)\end{array}$ & $\begin{array}{c}\text { Responder } \\
(\%)\end{array}$ & P value & (95\% CI, months) & $P$ value & (95\% CI, months) & P value \\
\hline \multicolumn{8}{|l|}{ CEA } \\
\hline$\leq$ Cutoff point & $24(30.8)$ & $54(69.2)$ & 0.001 & $7.8(7.0-8.6)$ & 0.029 & $18.8(13.4-24.2)$ & 0.0000 \\
\hline$>$ Cutoff point & $56(56.6)$ & $43(43.4)$ & & $5.3(3.6-7.0)$ & & $11.8(8.5-15.1)$ & \\
\hline \multicolumn{8}{|l|}{ CYFRA 21} \\
\hline$\leq$ Cutoff point & $29(38.7)$ & $46(61.3)$ & 0.134 & $7.8(6.6-9.0)$ & 0.230 & $14.5(10.6-18.4)$ & 0.677 \\
\hline$>$ Cutoff point & $51(50.0)$ & $51(50.0)$ & & $5.9(4.5-7.3)$ & & $16.5(12.0-21.0)$ & \\
\hline \multicolumn{8}{|l|}{ NSE } \\
\hline$\leq$ Cutoff point & $38(46.9)$ & $43(53.1)$ & 0.674 & $6.6(4.6-8.6)$ & 0.995 & $14.8(10.6-19.0)$ & 0.909 \\
\hline$>$ Cutoff point & $42(43.8)$ & $54(56.2)$ & & $6.9(4.7-9.1)$ & & $14.9(11.3-18.5)$ & \\
\hline \multicolumn{8}{|l|}{ CA199 } \\
\hline$\leq$ Cutoff point & $41(41.8)$ & $57(58.2)$ & 0.317 & $7.7(6.1-9.3)$ & 0.472 & $14.9(11.0-18.8)$ & 0.306 \\
\hline$>$ Cutoff point & $42(49.4)$ & $54(50.6)$ & & $5.6(4.2-7.1)$ & & $14.4(9.5-19.3)$ & \\
\hline \multicolumn{8}{|l|}{ Age } \\
\hline$<60$ & $40(48.2)$ & $43(51.8)$ & 0.452 & $5.5(4.0-7.0)$ & 0.300 & $14.1(10.9-17.3)$ & 0.08 \\
\hline$\geq 60$ & $40(42.6)$ & $54(57.4)$ & & $7.4(5.8-9.0)$ & & $16.7(12.3-21.1)$ & \\
\hline \multicolumn{8}{|l|}{ Gender } \\
\hline female & $39(42.4)$ & $53(57.6)$ & 0.435 & $7.2(5.8-8.6)$ & 0.213 & $17.5(11.0-24.0)$ & 0.151 \\
\hline male & $41(48.2)$ & $44(54.8)$ & & $5.9(4.4-7.4)$ & & $13.5(10.7-16.4)$ & \\
\hline \multicolumn{8}{|l|}{ Smoker } \\
\hline non-smoker & $52(43.0)$ & $69(57.0)$ & 0.382 & $6.9(5.8-8.0)$ & 0.644 & $16.3(13.4-19.2)$ & 0.696 \\
\hline current or ever & $28(50.0)$ & $28(50.0)$ & & $5.5(3.8-7.2)$ & & $13.4(10.3-16.5)$ & \\
\hline \multicolumn{8}{|l|}{ T stage } \\
\hline 1 or 2 & $43(48.9)$ & $45(51.1)$ & 0.330 & $6.8(5.1-8.6)$ & 0.719 & $16.7(10.7-22.8)$ & 0.259 \\
\hline 3 or 4 & $37(41.6)$ & $52(58.4)$ & & $6.6(4.7-8.6)$ & & $14.1(10.6-17.7)$ & \\
\hline \multicolumn{8}{|l|}{$\mathrm{N}$ stage } \\
\hline negative & $19(51.4)$ & $18(48.6)$ & 0.398 & $7.5(6.0-9.0)$ & 0.752 & $17.0(11.7-22.2)$ & 0.404 \\
\hline positive & $61(43.6)$ & $79(56.4)$ & & $6.6(5.1-8.1)$ & & $14.8(11.9-17.7)$ & \\
\hline \multicolumn{8}{|l|}{ Pleural effusion } \\
\hline none & $49(47.1)$ & $55(52.9)$ & 0.595 & $7.5(6.3-8.7)$ & 0.109 & $18.6(13.6-23.5)$ & 0.009 \\
\hline present & $31(43.1)$ & $41(56.9)$ & & $5.5(4.8-6.2)$ & & $11.5(9.8-13.2)$ & \\
\hline \multicolumn{8}{|l|}{ Lung metastasis } \\
\hline none & $43(46.2)$ & $50(53.8)$ & 0.825 & $6.8(5.1-8.6)$ & 0.416 & $14.9(9.7-20.1)$ & 0.566 \\
\hline present & $37(44.6)$ & $46(55.4)$ & & $6.6(4.8-8.5)$ & & $14.8(11.7-17.9)$ & \\
\hline \multicolumn{8}{|l|}{ Brain metastasis } \\
\hline none & $66(44.9)$ & $81(55.1)$ & 0.738 & $7.1(5.5-8.6)$ & 0.078 & $14.8(11.8-17.8)$ & 0.125 \\
\hline present & $14(48.3)$ & $15(51.7)$ & & $5.7(3.4-8.0)$ & & $14.8(8.1-21.4)$ & \\
\hline \multicolumn{8}{|l|}{ Bone metastasis } \\
\hline none & $37(44.6)$ & $46(55.4)$ & 0.876 & $6.6(5.0-8.2)$ & 0.985 & $14.9(9.7-20.0)$ & 0.387 \\
\hline present & $43(45.7)$ & $51(54.3)$ & & $6.9(4.5-9.3)$ & & $14.8(11.4-18.1)$ & \\
\hline \multicolumn{8}{|l|}{ Liver metastasis } \\
\hline none & $69(45.1)$ & $84(54.9)$ & 0.806 & $6.6(5.0-8.2)$ & 0.957 & $14.8(11.9-17.7)$ & 0.230 \\
\hline present & $11(47.8)$ & $12(52.2)$ & & $6.9(4.8-9.0)$ & & $14.4(10.2-18.6)$ & \\
\hline
\end{tabular}

$\mathrm{RR}=$ response rate $; \mathrm{PFS}=$ progression-free survival; $\mathrm{OS}=$ overall survival; $\mathrm{CI}=$ confidence interval. 

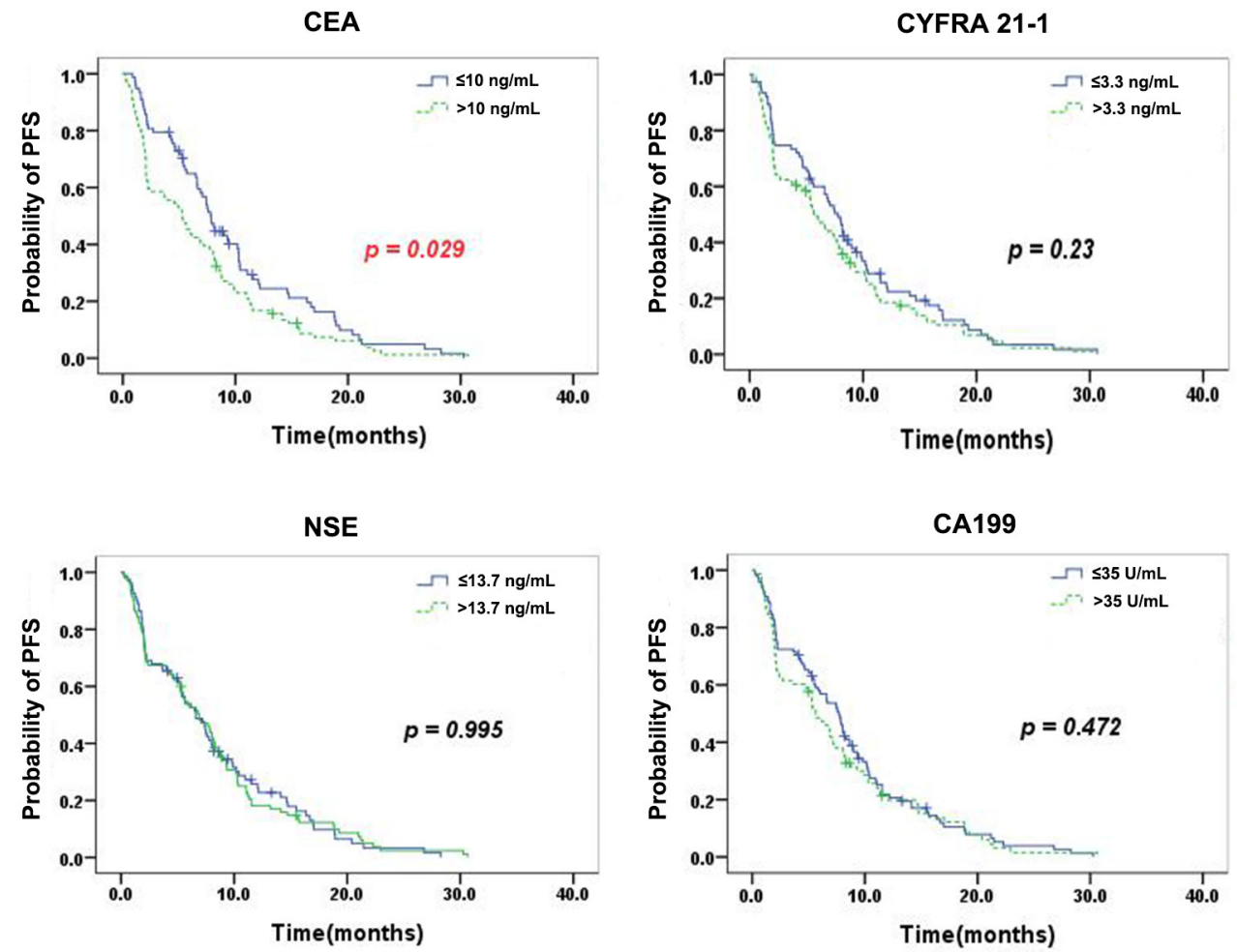

Figure 1: Kaplan-Meier curves for PFS according to the serum levels of single TMs. Patients with serum CEA levels below $10 \mathrm{ng} / \mathrm{mL}$ displayed a significantly improved $\mathrm{mPFS}$ for patients with higher CEA ( $\mathrm{p}=0.029)$. As for CYFRA 21-1, NSE, and CA199, there were no significant differences in mPFS between patients with low and elevated TM levels.
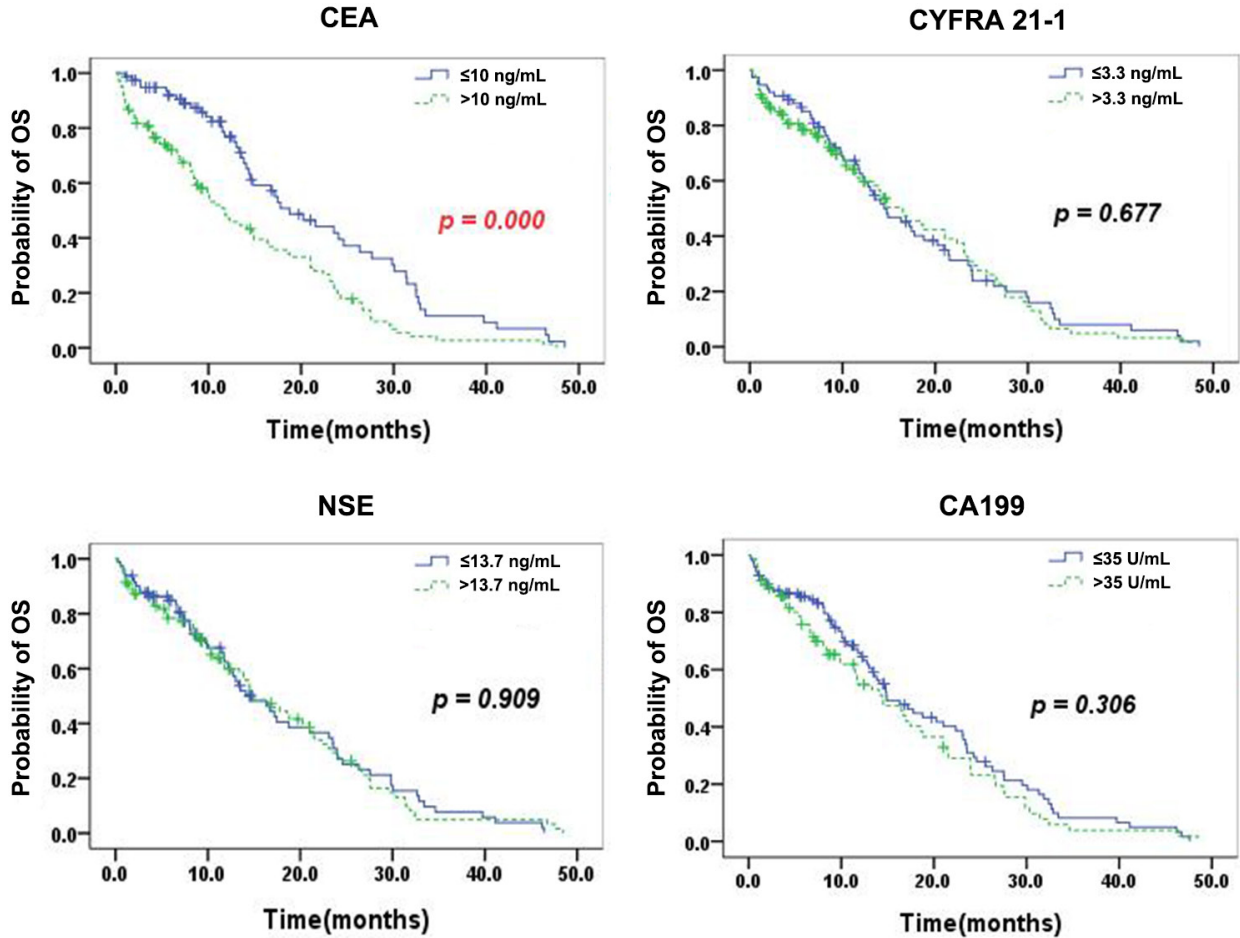

Figure 2: Kaplan-Meier curves for OS according to the serum levels of single TMs. Patients with normal serum CEA exhibited a significantly longer $\mathrm{mOS}$ than those with elevated CEA $(\mathrm{p}=0.000)$. No significant differences in $\mathrm{mOS}$ between patients with normal and high TM levels were observed (CYFRA 21-1, NSE, and CA199). 
Table 3: Multivariate analysis for RR, PFS and OS

\begin{tabular}{|c|c|c|c|c|c|c|c|c|c|}
\hline \multirow{2}{*}{ Variables } & \multicolumn{3}{|c|}{$\mathbf{R R}$} & \multicolumn{3}{|c|}{ PFS } & \multicolumn{3}{|c|}{ OS } \\
\hline & HR & $95 \%$ CI & $P$ value & HR & $95 \%$ CI & $P$ value & HR & $95 \%$ CI & $P$ value \\
\hline $\begin{array}{l}\text { CEA } \\
(>10 \mathrm{ng} / \mathrm{mL} \\
\mathrm{vs} \leq 10 \mathrm{ng} / \mathrm{mL})\end{array}$ & 0.322 & $0.166-0.625$ & 0.001 & 1.450 & $1.047-2.008$ & 0.025 & 2.133 & $1.444-3.151$ & 0.000 \\
\hline $\begin{array}{l}\text { CYFRA } 21-1 \\
(>3.3 \mathrm{ng} / \mathrm{ml} \\
\mathrm{vs} \leq 13.3 \mathrm{~g} / \mathrm{ml})\end{array}$ & 0.595 & $0.294-1.201$ & 0.147 & 1.217 & $0.871-1.702$ & 0.250 & 0.864 & $0.583-1.282$ & 0.468 \\
\hline $\begin{array}{l}\text { NSE } \\
(>13.7 \mathrm{ng} / \mathrm{mL} \\
\mathrm{vs} \leq 13.3 \mathrm{~g} / \mathrm{ml})\end{array}$ & 1.724 & $0.861-3.452$ & 0.124 & 0.838 & $0.598-1.173$ & 0.302 & 0.896 & $0.610-1.316$ & 0.576 \\
\hline $\begin{array}{l}\text { CA199 } \\
(>35 \mathrm{U} / \mathrm{ml} \\
\mathrm{vs} \leq 35 \mathrm{U} / \mathrm{ml})\end{array}$ & 0.788 & $0.416-1.492$ & 0.464 & 1.108 & $0.807-1.521$ & 0.527 & 1.277 & $0.898-1.816$ & 0.174 \\
\hline
\end{tabular}

$\mathrm{RR}=$ response rate $; \mathrm{PFS}=$ progression-free survival; $\mathrm{OS}=$ overall survival; $\mathrm{HR}=$ hazards ratio; $\mathrm{CI}=$ confidence interval.

\section{DISCUSSION}

In our study, we demonstrate that serum CEA levels are independent prognostic factors in TKI-treated stage IIIB and IV lung adenocarcinoma patients. We also show that a serum CEA level of less than $10 \mathrm{ng} / \mathrm{ml}$ was a predictor of favorable outcomes in advanced lung adenocarcinoma patients with EGFR-sensitive mutations (exon 19 deletion and L858R). In all patients, OS values were worse in conjunction with elevated values of serum tumor markers, but only in the case of CEA did this association reach statistical significance. Our study provide evidence that CEA levels may play a role in predicting the efficacy of EGFR TKIs, which is of great value for the selection of appropriate therapies.

The major strength of our study is that we chose a specific population. We excluded wild-type EGFR and T790M lung adenocarcinoma patients who were resistant to $1^{\text {st }}$-generation EGFR-TKIs such as Gefitinib and Erlotinib. And we included patients from 2009 and used AJCC lung cancer staging edition version 7 , the most recent version, to classify patients with malignant pleural effusion as stage IIIB. The prognoses of these patients were as poor as those classified as stage IV, due to more accurate prognostic factor analyses. To avoid interfering factors, we used a new staging system [16]. Besides, all patients received platinum-based chemotherapy as a first-line treatment and received EGFR-TKIs as a second- or third- line therapy, thus avoiding the interference of different lines of therapy. We did not analyze patients treated with first-line EGFR-TKIs, because in 2009, patients with EGFR exon 19 deletion mutations or L858R were not routinely treated with TKIs as a first-line therapy [17].

CEA is a very nonspecific tumor biomarker that shows elevated expression in various solid tumors. In lung cancer, inconsistent results have been published concerning the prognostic value of baseline CEA levels. In the Tomita et al [18] study of 291 stage I-III NSCLC patients, CEA was found to be a significant prognostic factor in patients with normal and high serum CEA levels, predicting $71.52 \%$ and $48.41 \%$ of cases, respectively $(\mathrm{p}<0.0001)$. In contrast to our study, Tomita et al recruited operable NSCLC patients, and after surgery all patients received adjuvant chemotherapy without TKIs. Moreover, their study did not determine EGFR status. Cedres et al [8] conducted a study to detect baseline CEA levels in 277 advanced-stage NSCLC patients and found that high baseline levels of tumor markers are correlated with worse survival in stage III-IV NSCLC patients. However, Cedres et al recruited patients with squamous cell carcinoma, large cell carcinoma, and adenocarcinoma, and they did not classify EGFR status [10]. In the Moro et al [12] study of 105 all-stage NSCLC patients, CEA was found to be a significant negative prognostic factor, but their study examined all-stage patients with different subtypes and used an older staging system. However, in studies from 
Ardizzoni et al. and Kulpa et al. of 107 patients with advanced-stage disease and of 200 patients of all stages, respectively, CEA was not found to be a prognostic factor for survival $[19,20]$.

In our study, the cutoff level for CEA was $10 \mathrm{ng} /$ $\mathrm{ml}$ and patients with CEA levels higher than $10 \mathrm{ng} / \mathrm{ml}$ had greater PFS and OS values. The cutoff level for CEA ranged between $2.5 \mathrm{ng} / \mathrm{ml}$ and $40 \mathrm{ng} / \mathrm{ml}$ in different studies [21]. These varying cutoff levels are likely due to different techniques and routines used in different testing centers. The results of some studies with cutoff values above 10 $\mathrm{ng} / \mathrm{ml}$ were quite similar to ours, showing the prognostic value of serum CEA levels and possibly demonstrating that the use of various tests to find the cutoff point provides the best description of the true value.

There is also some limitations in our study. Some biases were unavoidable due to chose two EGFR TKIsensitive mutations in the study, EGFR exon 19 deletion and L858R, which are both sensitive mutations but differ in their degree of sensitivity [22]. Additionally, our study sample size was small, as the patients were drawn from a single treatment center. These inconsistencies should be resolved by further external validations, preferably across multiple centers.

\section{CONCLUSION}

In this series of patients with advanced lung adenocarcinoma and EGFR-sensitive mutations who were treated with EGFR TKIs, CEA could be used as a significant predictive and prognostic tumor marker when selected $10 \mathrm{ng} / \mathrm{ml}$ as cut off point of pretreatment serum CEA levels.

\section{MATERIALS AND METHODS}

\section{Patients}

This study was conducted in the Department of Medical Oncology at Fudan University Shanghai Cancer Center between September 2009 and August 2013. A total of 177 patients were deemed eligible on the basis of the following criteria: (1) histopathologically confirmed, locally advanced or metastatic pulmonary adenocarcinoma harboring EGFR exon 18-21 mutations, except for those with an exon 20 mutation only; (2) receiving platinum-based chemotherapy as a first-line therapy; (3) receiving EGFR TKIs as a second- or thirdline therapy; (4) available tumor marker (TM) data before treatment with EGFR TKIs; and (5) available follow-up data. Demographic and clinical characteristics, including gender, age at diagnosis of lung cancer or recurrence $(<$ 60 or $\geq 60$ years), smoking status, TNM staging status, and presence of metastatic organs at the time of treatment with TKIs were collected. Baseline circulating TMs were analyzed as potential predictive and prognostic factors.
This study was approved by the Ethics Committee of Fudan University prior to commencing.

\section{Treatment and evaluation of therapeutic efficacy}

All 177 patients received platinum-based chemotherapy as a first-line therapy and EGFR TKIs as a second- or third-line therapy for at least one month. Gefitinib was given at a dose of $250 \mathrm{mg} \mathrm{qd}$, and Erlotinib was given at a dose of $150 \mathrm{mg}$ qd. The numbers of metastatic sites at the diagnosis were counted on computed tomographic images, brain magnetic resonance images, whole body bone scans. The tumor response was assessed based on the Response Evaluation Criteria in Solid Tumors (RECIST) version 1.1 [15].

\section{Tumor marker detection}

The serum levels of TMs, including CEA, CYFRA 21-1, NSE, and CA199, were tested before EGFR TKI treatment using a chemiluminescence immunoassay. Four TMs were tested in a single laboratory and the cut-off values for each marker were $10 \mathrm{ng} / \mathrm{mL}$ for CEA, $3.3 \mathrm{ng} /$ $\mathrm{mL}$ for CYFRA-21, $13.7 \mathrm{ng} / \mathrm{mL}$ for NSE, and $35 \mathrm{U} / \mathrm{ml}$ for CA19-9. Baseline serum levels of TMs were considered available if they were tested within one week before EGFR TKI treatment began.

\section{Statistical analysis}

Statistically significant differences in categorical variables between predictive factors and response rate (RR) were analyzed Pearson's $\chi 2$ test or Fisher's exact test as appropriate. Progression-free survival (PFS) is defined as the time from the date of starting EGFR-TKI treatment to the date of disease progression or death from any cause, if a patient died earlier; surviving patients without progression were evaluated at their most recent follow-up. Overall survival (OS) was calculated from the start of the first-line treatment of advanced disease to the date of death or the last follow-up. PFS and OS were estimated by the Kaplan-Meier method. The association between predictive factors and PFS or OS was explored using a log-rank test. The Cox proportional hazards regression model was used to determine the hazards ratios (HR) and $95 \%$ confidence intervals (CIs) in the univariate and multivariate survival analyses. Two-sided values of $\mathrm{P}<0.05$ were considered statistically significant.

\section{Abbreviations}

NSCLC: non-small-cell lung cancer; EGFR: epidermal growth factor receptor; TKIs: tyrosine kinase inhibitors; TMs: tumor markers; CEA: carcinoembryonic antigen; PFS: progression-free survival; RR: response rate; OS: overall survival. 


\section{Author contributions}

Conception and design: Xiang Hua $\mathrm{Wu}$

Collection and assembly of data: Xin min Zhao, Jing Zhao, Kai Lin Xing, Si Sun, Zhi Guo Luo, Hui Jie Wang, Jia Lei Wang, Jian Hua Chang and Xiang Hua Wu

Biomarkers detection: Xin min Zhao, Jing Zhao, Kai Lin Xing Zhao

Data analysis and interpretation: Xin min Zhao, Jing

Manuscript writing: Xin min Zhao, Jing Zhao

Final approval of manuscript: Xin min Zhao, Jing Zhao, Kai Lin Xing, Si Sun, Zhi Guo Luo, Hui Jie Wang, Jia Lei Wang, Jian Hua Chang and Xiang Hua Wu

\section{ACKNOWLEDGMENTS}

We thank all the investigators and enrolled patients for our study.

\section{CONFLICTS OF INTEREST}

No potential conflicts of interest were disclosed.

\section{FUNDING}

This work was supported by grants from Nature Science Foundation of China (no.81302009) and Shanghai Nature Science Foundation (no.12ZR1406500), Shanghai Nature Science Foundation (no.12ZR1406400).

\section{REFERENCES}

1. Siegel R, Naishadham D, Jemal A. Cancer statistics. Cancer J Clin. 2012; 62:10-29. https://doi.org/10.3322/caac.20138.

2. Siegel R, Desantis C, Virgo K, Stein K, Mariotto A, Smith T, Cooper D, Gansler T, Lerro C, Fedewa S, Lin C, Leach $\mathrm{C}$, Cannady RS, et al. Cancer treatment and survivorship statistics. CA Cancer J Clin. 2012; 62:220-41. https://doi. org/10.3322/caac.21149.

3. Harari PM, Allen GW, Bonner JA. Biology of interactions antiepidermal growth factor receptor agents. J Clin Oncol. 2007; 25:4057-65. https://doi.org/10.1200/ JCO.2007.11.8984.

4. Hynes NE, Lane HA. ERBB receptors and cancer: the complexity of targeted inhibitors. Nat Rev Cancer. 2005; 5:341-54. https://doi.org/10.1038/nrc1609.

5. Jarvisalo J, Hakama M, Knekt P, Stenman UH, Leino A, Teppo L. Serum tumor markers CEA, CA 50, TATI, and NSE in lung cancer screening. Cancer. 1993; 71:1982-8. https:// doi.org/10.1002/1097-0142(19930315)71:6<1982::AIDCNCR2820710610>3.0.CO;2-G.

6. Buccheri G, Biggi A, Ferrigno D, Leone A, Taviani M, Quaranta M. Anti-CEA immunoscintigraphy might be more useful than computed tomography in the preoperative thoracic evaluation of lung cancer. A comparison between planar immunoscintigraphy, single photon emission computed tomography (SPECT), and computed tomography. Chest. 1993; 104:734-42. https://doi. org/10.1378/chest.104.3.734.

7. Ogushi F, Fukuoka M, Takada M, Tamai S, Sakai N, Negoro S, Okunaka N, Sone S, Tsubura E. Carcinoembryonic antigen (CEA) levels in pleural effusions and sera of lung cancer patients. Jpn J Clin Oncol. 1984; 14:321-7. https:// doi.org/10.1093/oxfordjournals.jjco.a038985.

8. Cedres S, Nunez I, Longo M, Martinez P, Checa E, Torrejon D, Pelip E. Serum tumor markers CEA, CYFRA21-1, and CA-125 are associated with worse prognosis in advanced non-small-cell lung cancer (NSCLC). Clin Lung Cancer. 2011; 12:172-9. https://doi.org/10.1016/j.cllc.2011.03.019.

9. Krauss S, Macy S, Ichiki AT. A study of immunoreactive calcitonin (CT), adrenocorticotropic hormone (ACTH) and carcinoembryonic antigen (CEA) in lung cancer and other malignancies. Cancer. 1981; 47:2485-92. https:// doi.org/10.1002/1097-0142(19810515)47:10<2485::AIDCNCR2820471029>3.0.CO;2-C.

10. Arrieta $\mathrm{O}$, Villarreal-Garza $\mathrm{C}$, Martinez-Barrera L, Morales M, Dorantes-Gallareta Y, Pena-Curiel O, ContrerasReyes S, Macedo-Perez EO, Alatorre-Alexander J. Usefulness of serum carcinoembryonic antigen (CEA) in evaluating response to chemotherapy in patients with advanced non small-cell lung cancer: a prospective cohort study. BMC Cancer. 2013; 13:254. https://doi. org/10.1186/1471-2407-13-254.

11. Chu XY, Hou XB, Song WA, Xue ZQ, Wang B, Zhang LB. Diagnostic values of SCC, CEA, Cyfra21-1 and NSE for lung cancer in patients with suspicious pulmonary masses: a single center analysis. Cancer Biol Ther. 2011; 11:9951000. https://doi.org/10.4161/cbt.11.12.15526.

12. Moro D, Villemain D, Vuillez JP, Delord CA, Brambilla C. CEA, CYFRA21-1 and SCC in non-small cell lung cancer. Lung Cancer. 1995; 13:169-76. https://doi. org/10.1016/0169-5002(95)00485-8.

13. Hanagiri T, Sugaya M, Takenaka M, Oka S, Baba T, Shigematsu Y, Nagata Y, Shimokawa H, Uramoto H, Takenoyama M, Yasumoto K, Tanaka F. Preoperative CYFRA 21-1 and CEA as prognostic factors in patients with stage I non-small cell lung cancer. Lung Cancer. 2011; 74:112-7. https://doi.org/10.1159/000152945.

14. Chen VW, Ruiz BA, Hsieh MC, Wu XC, Ries LA, Lewis DR. Analysis of stage and clinical/prognostic factors for lung cancer from SEER registries: AJCC staging and collaborative stage data collection system. Cancer. 2014; 120:3781-92. https://doi.org/10.1002/cncr.29045.

15. Eisenhauer EA, Therasse P, Bogaerts J, Schwartz LH, Sargent D, Ford R, Dancey J, Arbuck S, Gwyther S, Mooney M, Rubinstein L, Shankar L, Dodd L, et al. New response evaluation criteria in solid tumours: revised 
RECIST guideline (version 1.1). Eur J Cancer. 2009; 45:228-47. https://doi.org/10.1016/j.ejca.2008.10.026.

16. Saijo N, Takeuchi M, Kunitoh H. Reasons for response differences seen in the V15-32, INTEREST and IPASS trials. Nat Rev Clin Oncol. 2009; 6:287-94. https://doi. org/10.1038/nrclinonc.2009.37.

17. Pujol JL, Molinier O, Ebert W, Daures JP, Barlesi F, Buccheri G, Paesmans M, Quoix E, Moro-Sibilot D, Szturmowicz M, Brechot JM, Muley T, Grenier J. CYFRA 21-1 is a prognostic determinant in non-small-cell lung cancer: results of a meta-analysis in 2063 patients. $\mathrm{Br}$ J Cancer. 2004; 90:2097-105. https://doi.org/10.1038/ sj.bjc. 6601851 .

18. Tomita M, Shimizu T, Ayabe T, Yonei A, Onitsuka T. Prognostic significance of tumour marker index based on preoperative CEA and CYFRA 21-1 in non-small cell lung cancer. Anticancer Res. 2010; 30:3099-102.

19. Ardizzoni A, Cafferata MA, Tiseo M, Filiberti R, Marroni P, Grossi F, Paganuzzi M. Decline in serum carcinoembryonic antigen and cytokeratin 19 fragment during chemotherapy predicts objective response and survival in patients with advanced nonsmall cell lung cancer. Cancer. 2006; 107:2842-9. https://doi.org/10.1002/cncr.22330.

20. Kulpa J, Wojcik E, Reinfuss M, Kolodziejski L. Carcinoembryonic antigen, squamous cell carcinoma antigen, CYFRA 21-1, and neuron-specific enolase in squamous cell lung cancer patients. Clin Chem. 2002; 48:1931-7.

21. Fiala O, Pesek M, Finek J, Benesova L, Minarik M, Bortlicek Z, Topolcan O. Predictive role of CEA and CYFRA 21-1 in patients with advanced-stage NSCLC treated with erlotinib. Anticancer Res. 2014; 34:3205-10.

22. Shaozhang Z, Ming Z, Haiyan P, Aiping Z, Qitao Y, Xiangqun S. Comparison of ARMS and direct sequencing for detection of EGFR mutation and prediction of EGFRTKI efficacy between surgery and biopsy tumor tissues in NSCLC patients. Med Oncol. 2014; 31:926. https://doi. org/10.1007/s12032-014-0926-3. 